\title{
Trade-off between hunting ability and starvation tolerance in the wolf spider, Pardosa pseudoannulata (Araneae: Lycosidae)
}

\author{
Hiroyuki IIDA* \\ Laboratory of Insect Ecology, Graduate School of Agriculture, Kyoto University; Kyoto 606-8502, Japan
}

(Received 18 November 2003; Accepted 26 August 2004)

\begin{abstract}
Experiments were conducted to investigate whether there is a trade-off between hunting ability and starvation tolerance in spiderlings of a wandering spider, Pardosa pseudoannulata Boes. et Str. The width of the carapace (the cover over the cephalothorax) was used as an index of hunting ability, as a larger carapace was confirmed as being advantageous for capturing prey. Abdomen width was used as an index of starvation tolerance because individuals with larger abdomens survived longer under fasting condition. Effects of carapace width and abdomen width on starvation tolerance were examined using multiple regression analysis. The carapace width was found to have a negative effect but the abdomen width had a positive effect on starvation tolerance. Moreover, the ratio of abdomen width to carapace width was significantly different among clutches. These results suggested that there is a trade-off between carapace width and abdomen width, that is, between hunting ability and starvation tolerance, and also suggested that the tradeoff might be an allocation strategy specific to each clutch.
\end{abstract}

Key words: Pardosa pseudoannulata; body size; allocation strategy; wolf spider; trade-off

\section{INTRODUCTION}

Trade-offs have a central role in life history theory (Stearns, 1992). Among various trade-offs a large number of studies have focused exclusively on a trade-off between egg number and egg size (Lack, 1954; Itô, 1978). It should be noted, however, that theories have implicitly assumed that resource allocation within an egg is fixed among mothers. If mothers can allocate resource differentially into different parts of an embryo in relation to future prospect of food conditions for their offspring, the maternal allocation strategy may have adaptive significance. This study experimentally examined the trade-off between hunting ability and starvation tolerance of the neonates in a wolf spider, Pardosa pseudoannulata Boes. et Str., widely known as a key predator of insect pests in paddy fields (Yaginuma, 1986). Both abilities have been regarded to be extremely important because carnivores live under fluctuating and unpredictable food conditions (Hairston et al., 1960; Miyashita, 1968; Anderson, 1974; Wise, 1975).

A spider's body consists essentially of two parts: a cephalothorax and an abdomen (Foelix, 1982). The width of the carapace that covers the cephalothorax is often used as an index of a spider's body size, which may directly and/or indirectly determine hunting ability. For example, in an orb weaving spider, Argiope amonea, individuals with large carapace width can prey on larger organisms than those with small carapace width $(\mathrm{Mu}-$ rakami, 1983). Among spiderlings of $P$. pseudoannulata, individuals with larger carapace widths had an advantage with respect to cannabalism over those with smaller carapaces (Iida, 2003). On the other hand, a spider's abdomen is highly distensible and contains many diverticula (Butt and Taylor, 1986; Yoshikura, 1987). In times of food shortage, spiders survive starvation by consuming lipids that have accumulated in their abdomen (Tanaka et al., 1985; Tanaka, 1995). Hence, abdomen size would be applicable as an index of starvation tolerance.

Both hunting ability and starvation tolerance are of critical importance; however, a trade-off may exist between them as long as egg size is limited. In addition, large variation in egg size may mask the trade-off because both carapace width and ab-

* E-mail: iida@kais.kyoto-u.ac.jp

DOI: 10.1303/aez.2005.47 
domen width would be positively correlated with egg size. This may explain why few studies have ever detected the trade-off. To exclude such putative effect of egg size, multiple regression analysis of carapace width and abdomen width on starvation tolerance was conducted.

\section{MATERIALS AND METHODS}

The wolf spider, $P$ pseudoannulata. $P$. pseudoannulata is a wandering spider that primarily inhabits paddy fields and preys on planthoppers and leafhoppers (Kiritani et al., 1972). Two or three generations are produced each year (Kawahara et al., 1974), leading to coexistence of various instars. This species is an iteroparous spider; for each egg mass a female makes a sac and attaches it to her abdomen until the nymphs emerge. The first instar nymphs molt within the egg sac and emerge as second instars. Once emerged, the spiderlings cling in a group to their mother's abdomen for several days and then disperse (Rovner and Higashi, 1973; Fujii, 1989). During this gregarious period, the spiderlings take in some water but do not eat (Yoshikura, 1987).

Preparation of the spiderlings. Adult $P$. pseudoannulata were collected from a rice field in the environs of Kyoto City, Japan, in October and November 2002. Each spider was reared individually in a plastic cup $(100 \mathrm{~mm}$ in diameter and $45 \mathrm{~mm}$ in depth) with a piece of moistened cotton for humidity. The spiders were supplied with green bottle flies, Phaenicia cuprina and P. sericata, and small brown planthoppers, Laodelphax striatellus. Rearing and experiments were conducted in the laboratory at $25^{\circ} \mathrm{C}$ and under a $16: 8$ light: dark cycle. In total, 23 egg sacs from 23 females were used for the analysis of the relationship among carapace width, abdomen width, and starvation tolerance of spiderlings.

Measurement of body size of spiderlings. Two days after oviposition, each egg sac was opened, and then eggs of each clutch were divided into groups of approximately 20 eggs to standardize the rearing density. Each group of eggs was placed into a cotton-plugged glass vial $(2.0 \mathrm{ml})$, and the vials were kept within a plastic cup $(130 \mathrm{~mm}$ in diameter and $55 \mathrm{~mm}$ in depth), which contained moist cotton, and was covered by a lid with air holes. Hatched nymphs were kept in the glass vials until reaching the second-instar stage. In principle, a total of 30 spiderlings were collected from each clutch by randomly selecting approximately the same number of spiderlings from each of the glass vials. For two clutches, however, 18 and 28 spiderlings were used, respectively, since no other nymphs developed into second instars in these clutches. Carapace and abdomen widths of the selected spiderlings were measured to the nearest $0.02 \mathrm{~mm}$ under a binocular microscope. Furthermore, the value of abdomen width divided by carapace width (hereafter noted as abdomen-carapace ratio) was calculated to quantify the resource allocation of a spiderling.

Starvation tolerance of spiderlings. After measurement of carapace width and abdomen width, the spiderlings were reared individually without food but with moistened cotton in a glass vial $(1.8 \mathrm{ml})$. The number of days they survived was recorded and used as an index of their starvation tolerance.

Hunting ability of spiderlings. The rest of the nymphs that were not used for measurement of body size were also reared in the procedure above to examine their hunting ability. They were kept in glass vials $(1.8 \mathrm{ml})$ without food for $5 \mathrm{~d}$ after molting to the second-instar nymphs. On the next day, carapace width of spiderlings was measured to the nearest $0.02 \mathrm{~mm}$ under a binocular microscope. Second-instar nymphs with various carapace widths were arbitrarily chosen regardless of their natal egg sacs and individually introduced into a $2.0 \mathrm{ml}$ glass vial together with a male adult of small brown planthopper, L. striatellus, to quantify size dependent hunting success. If a spiderling could not capture the prey in spite of the close contact between them, the nymph was regarded to have failed the hunt. The trial was conducted once for every spiderling in each carapace width category, $0.64,0.66,0.68,0.70,0.72$ and $0.74 \mathrm{~mm}$. The sample size in each category was $28,30,30,30,26$, and 11 , respectively.

\section{RESULTS}

\section{Spiderling body size and starvation tolerance}

The mean $( \pm$ SD) and range of the carapace width, abdomen width, abdomen-carapace ratio, and starvation tolerance are shown in Table 1. Moreover, coefficient of variation $(\mathrm{CV})$ in each 
Table 1. Carapace width $(\mathrm{mm})$, abdomen width $(\mathrm{mm})$, abdomen width/carapace width (abdomen-carapace ratio), and starvation tolerance (d) of 23 egg sacs of $P$. pseudoannulata

\begin{tabular}{lcccc}
\hline & Carapace width & Abdomen width & Abdomen-carapace ratio & Starvation tolerance \\
\hline Mean & 0.66 & 0.51 & 0.78 & 23.4 \\
SD $^{\mathrm{a}}$ & 0.019 & 0.022 & 0.039 & 3.7 \\
Range of mean $^{\mathrm{b}}$ & $0.63-0.70$ & $0.47-0.55$ & $0.71-0.87$ & $16.4-30.1$ \\
Inter-clutch CV (\%) $^{\mathrm{c}}$ & 2.9 & 4.3 & 5.0 & 15.8 \\
Intra-clutch CV (\%) $^{\mathrm{d}}$ & 2.8 & 4.9 & 4.6 & 9.3 \\
\hline
\end{tabular}

${ }^{a} \mathrm{SD}$ : standard deviation of mean value of each clutch data.

${ }^{\mathrm{b}}$ Range shows minimum and maximum of mean value of each clutch data.

${ }^{\mathrm{c}}$ Inter-clutch CV was calculated using 23 means and SDs for 23 clutches.

${ }^{\mathrm{d}}$ Intra-clutch $\mathrm{CV}$ is a mean of $\mathrm{CV}$ for 23 clutches.

Table 2. One way factorial ANOVA table for carapace width, abdomen width, and abdomen-carapace ratio of spiderlings among clutches

\begin{tabular}{llrrrr}
\hline \multicolumn{1}{c}{ Source } & & df & MS & $F$ & $p$ \\
\hline Carapace width & Inter-clutch variation & 22 & 0.011093 & 28.3 & $<0.001$ \\
& Error & 653 & 0.000392 & & \\
Abdomen width & Inter-clutch variation & 22 & 0.013792 & 19.2 & $<0.001$ \\
& Error & 653 & 0.000718 & & \\
Abdomen-carapace ratio & Inter-clutch variation & 22 & 0.044392 & 32.9 & $<0.001$ \\
& Error & 653 & 0.001351 & & \\
\hline
\end{tabular}

variable was calculated for both inter-clutches and intra-clutch. Consequently, CVs of carapace width were considerably small $(2.8-2.9 \%)$, but CVs of abdomen width and of abdomen-carapace ratio were $4.3-5.0 \%$, and starvation tolerance varied greatly, particularly among clutches $(15.8 \%$ in $\mathrm{CV})$. Overall, CVs of body sizes were similar between within-clutch and among-clutches. To determine whether each mother produces offspring of specific sizes and of specific abdomen-carapace ratio, means of the carapace width, the abdomen width, and the abdomen-carapace ratio were compared among clutches. As a result, all of these were significantly different among clutches (Table 2). Furthermore, results of Tukey's HSD test $(p=0.05)$ showed that the 23 clutches were divided into 10 , 10 , and 11 groups within which no significant difference was detected for carapace width, abdomen width, and abdomen-carapace ratio, respectively.

\section{Indices of starvation tolerance and hunting abil- ity}

Abdomen width exhibited a significant and positive correlation with starvation tolerance (Fig. 1), thus abdomen width was applicable as an index of

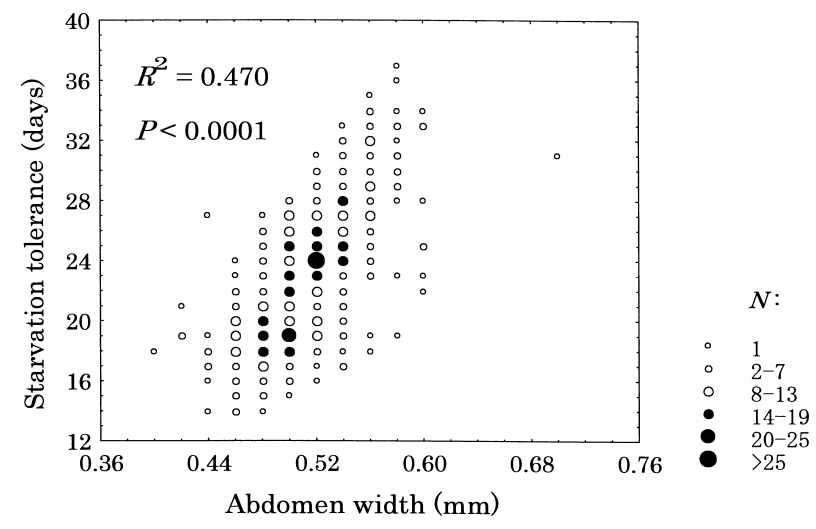

Fig. 1. Relationship between abdomen width and starvation tolerance $(n=676)$. Differences in dot size and color reflect the differences in sample size. Relationship between kinds of dots and sample sizes $(N)$ are shown in the right side of the figure.

starvation tolerance. On the other hand, the rate of hunting success for each carapace width $(0.64$, $0.66,0.68,0.70,0.72$, and $0.74 \mathrm{~mm}$ ) was 0.33 , $0.33,0.43,0.67,0.65$, and 0.73 , respectively. Regression analysis revealed that there was a highly significant and positive correlation between carapace width and the rate of hunting success (Fig. 2). This result implied that carapace width was an ap- 


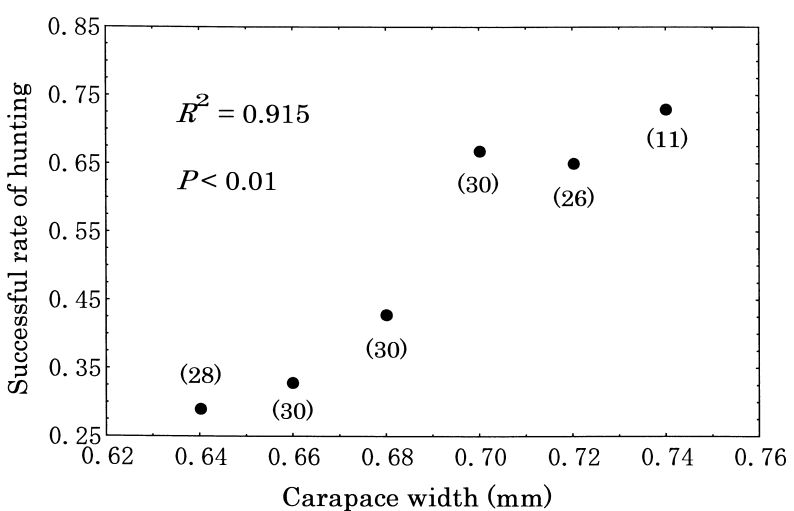

Fig. 2. Relationship between carapace width and hunting ability. Number in parentheses is the number of spiderlings examined.

Table 3. Multiple regression analysis of the relationship between starvation tolerance and other two traits: carapace width and abdomen width

\begin{tabular}{crrl}
\hline Parameter & Partial correlation & Semipartial & \multicolumn{1}{c}{$p$} \\
\hline Carapace width & -0.529 & -0.312 & $<0.05$ \\
Abdomen width & 0.857 & 0.830 & $<0.0001$ \\
\hline
\end{tabular}

$R^{2}=0.751 ; F=30.1 ; \mathrm{df}=2,20 ; N=23 ; p<0.0001$.

propriate index of the hunting ability of spiderlings in P. pseudoannulata.

\section{Trade-off between hunting ability and starva- tion tolerance}

Relationship between carapace width and abdomen width was examined first to detect the trade-off between hunting ability and starvation tolerance. There was no correlation between the two variables $\left(R^{2}=0.00603, p>0.05\right)$, and the carapace width was not correlated with the starvation tolerance $\left(R^{2}=0.0614, p>0.05\right)$. Next, multiple regression analysis of starvation tolerance on carapace width and abdomen width was conducted to incorporate both effects of the two explanatory variants in the analysis. The carapace width was found to have a negative effect on starvation tolerance in contrast with the abdomen width (Table 3).

\section{DISCUSSION}

The result of the multiple regression analysis suggested that there was a trade-off between hunting ability and starvation tolerance in $P$. pseudoan- nulata spiderlings, though no correlation was detected between them by a simple regression analysis. The discrepancy could be attributed to the different quantity of maternal investment per egg among clutches; for example, spiderlings from larger eggs could have a larger cephalothorax and larger abdomen, while those from smaller eggs could have a smaller cephalothorax and smaller abdomen. If these data are plotted, a positive correlation should appear between them. Accordingly, variation in maternal investment per egg may mask the trade-off. Multiple regression analysis at least partly excluded the disturbance and could detect the trade-off. Previous studies, however, did not confirm the trade-off between carapace width and starvation tolerance (e.g., Tanaka, 1995; Walker et al., 2003). If heterogeneity of maternal investment into an egg was adjusted, the trade-off might have been detected in these studies.

Why does larger carapace width suppress starvation tolerance? The cephalothorax has more muscles, which consume more energy when moving, than does the abdomen (Yoshikura, 1987). Consequently, individuals with a larger cephalothorax must have more muscles than smaller individuals. Spiderlings with a larger cephalothorax therefore may consume more energy, so as to have a lower starvation tolerance as long as abdomen size is fixed.

Allocation of egg resources would appreciably affect the trade-off between hunting ability and starvation tolerance. If greater egg resources are allocated to either of the two body parts, then the other body part will obtain fewer resources, suggesting a potential trade-off between cephalothorax and abdomen sizes. Both hunting ability and starvation tolerance were important, but the results showed that they were antagonistic traits for spiders. Hence, if female spiders can predict environmental suitability for their progeny based on their own experience of environmental conditions, they will determine the optimal size ratio of cephalothorax to abdomen for spiderlings in response to relative importance of hunting ability and starvation tolerance. For instance, if hunting opportunity for spiderlings decreases with time, mothers may allocate more egg resources to the cephalothorax than to the abdomen to enhance present hunting ability at the sacrifice of future hunting opportunities.

ANOVA for body sizes of spiderlings showed 
that carapace width, abdomen width, and abdomen-carapace ratio were specific for each clutch. The important point to note is that the abdomencarapace ratio varied largely in comparison with the carapace width and the abdomen width. The ratio varied from 0.71 to 0.87 (Table 1), which was translated to 0.36 to 0.66 variation in volume. Hence, the maximum/minimum ratio was 1.83 , whereas it was 1.37 for carapace width and 1.60 for abdomen width. Thus, allocation of maternal investment between cephalothorax and abdomen of a spiderling differed greatly among mothers, though all mothers were reared under the same feeding conditions, temperature, and photoperiod in this study. This may be because the allocation had a certain genetic basis. If so, each mother might have a specific allocation strategy, otherwise, mother spiders might respond differently to the same environmental cues or simply be unable to control the spiderling size accurately due to physiological constraints.

CVs of body sizes and of abdomen-carapace ratio were similar between inter-clutches and intraclutch. Hence, mothers of $P$. pseudoannulata may equalize the amounts of investment per offspring rather than employ a bet-hedging strategy (Schaffer, 1974; Stearns, 1992). In this experiment, equality of rearing conditions would have diminished the inter-clutch CVs. If mother spiders were allowed to oviposit under various environmental conditions, inter-clutch CVs might have been apparently larger than intra-clutch ones.

Unfortunately, no causal mechanisms are known as to how mother spiders allocate egg resources between cephalothorax and abdomen. In the rainbow trout, photoperiod influences gonadotropin, which affects egg size, that is amount of investment into an egg (Bon et al., 1999). If a certain endocrine mechanism controls the allocation of egg resources in response to environmental cues in P. pseudoannulata, the allocation strategy would be adaptive. Alternatively, offspring may change their own size ratio between cephalothorax and abdomen in response to some environmental cues. To elucidate which mechanism is responsible, further investigation is required.

\section{ACKNOWLEDGEMENTS}

I would like to thank Drs. E. Kuno, K. Fujisaki, N. Osaki, and T. Nishida of Kyoto University for their encouragement and valuable suggestions. I wish to thank Dr. K. Yamazaki of Osaka City Institute of Public Health and Environmental Sciences for identification of planthoppers. My thanks are also due to Dr. T. Matsui at the experimental farm, Kyoto University, for kindly supplying rough rice for rearing planthoppers.

\section{REFERENCES}

Anderson, J. F. (1974) Responses to starvation in the spiders Lycosa lenta (Hentz) and Filistata hibernalis (Hentz). Ecology 55: 576-585.

Bon, E., B. Breton, M. S. Govoroun and F. Le Menn (1999) Effects of accelerated photoperiod regimes on the reproductive cycle of the female rainbow trout: II Seasonal variations of plasma gonadotropins (GTH I and GTH II) levels correlated with ovarian follicle growth and egg size. Fish Physiol. Biochem. 20: 143-154.

Butt, A. G. and H. H. Taylor (1986) Salt and water balance in the spider, Porrhothele antipodiana (Mygalomorpha: Dipluridae): effects of feeding upon hydrated animals. J. Exp. Biol. 125: 85-106.

Foelix, R. F. (1982) Biology of Spiders. Harvard University Press, Massachusetts and London. $306 \mathrm{pp.}$

Fujii, Y. (1989) Walking nursery school: Maternal care of wolf spiders. In Reports about Spiders I (K. Umeya and K. Katoh eds.). Gihodo Syuppan, Tokyo, pp. 53-61 (in Japanese).

Hairston, N. G., F. E. Smith and L. B. Slobodkin (1960) Community structure, population control, and competition. Am. Nat. 94: 421-425.

Iida, H. (2003) Small within-clutch variance in spiderlings body size as a mechanism for avoiding sibling cannibalism in the wolf spider Pardosa pseudoannulata (Araneae: Lycosidae). Popul. Ecol. 45: 1-6.

Itô, Y. (1978) Comparative Ecology. Iwanami Publ., Tokyo. 421 pp. (in Japanese).

Kawahara, S., K. Kiritani and N. Kakiya (1974) Population ecology of Lycosa pseudoannulata Boes et. Str. (Araneae: Licosidae). Bull. Kohchi Prefect. Inst. Agric. Sci. 6: $7-22$.

Kiritani, K., S. Kawahara, T. Sasaba and F. Nakasuji (1972) Quantitative evaluation of predation by spiders on the green rice leafhopper, Nephotettix cincticeps Uhler, by a sight-count method. Res. Popul. Ecol. 13: 187-200.

Lack, D. (1954) The evolution of reproductive rates. In Evolution as a Process (J. Huxley, A. C. Hardy and E. B. Ford eds.). G. Allen \& Unwin, London, pp. 143-156.

Miyashita, K. (1968) Growth and development of Lycosa T-insignita Boes. et Str. (Araneae: Lycosidae) under different feeding conditions. Appl. Entomol. Zool. 3: $81-88$.

Murakami, Y. (1983) Factors determining the prey size of the orb-web spider, Argiope amoena (Argiopidae). Oecologia 57: 72-77.

Rovner, J. S. and G. A. Higashi (1973) Maternal behavior in wolf spiders: the role of abdominal hairs. Science 182: 1153-1155.

Schaffer, W. M. (1974) Optimal reproductive effort in fluctu- 
ating environments. Am. Nat. 108: 783-790.

Stearns, S. C. (1992) The Evolution of Life Histories. Oxford University Press, Oxford. $249 \mathrm{pp}$.

Tanaka, K. (1995) Variation in offspring size within a population of the web-building spider Agelena limbata. Res. Popul. Ecol. 37: 197-202.

Tanaka, K., Y. Itô and T. Saito (1985) Reduced respiratory quotient by starvation in a wolf spider, Pardosa astrigera (L. Koch). Comp. Biochem. Physiol. 80A: 415-418.

Walker, S. E., A. L. Rypstra and S. D. Marshall (2003) The relationship between offspring size and performance in the wolf spider Hogna helluo (Araneae: Lycosidae). Evol. Ecol. Res. 5: 19-28.

Wise, D. H. (1975) Food limitation of the spider Linyphia marginata: experimental field studies. Ecology 56: 637-646.

Yaginuma, T. (1986) Spiders of Japan in Color (new ed.). Hoikusha Publ., Osaka. 305 pp. (in Japanese).

Yoshikura, M. (1987) The Biology of Spiders. Gakkai Syuppan Center, Tokyo. 613 pp. (in Japanese). 